\title{
Expression and the antigenicity of recombinant coat proteins of tungro viruses expressed in Escherichia coli
}

\author{
Yee Siew Fung a,b, Chu Chia Huay ${ }^{a}$, Evenni Poili ${ }^{c}$, Magdline Sia Henry Sum ${ }^{\mathrm{a}, *}$ \\ a Institute of Health and Community Medicine, Universiti Malaysia Sarawak, 94300 Kota Samarahan, Sarawak, Malaysia \\ ${ }^{\mathrm{b}}$ Agriculture Research Centre Semongok, Department of Agriculture, Sarawak, Jalan Puncak Borneo, 93720 Kuching, Sarawak, Malaysia \\ ${ }^{\mathrm{c}}$ Agriculture Research Centre Tuaran, Department of Agriculture, Sabah, P.O. Box No. 3, 89207 Tuaran, Sabah, Malaysia
}

\section{Article history:}

Received 18 February 2016

Received in revised form 2 September 2016

Accepted 2 December 2016

Available online 5 December 2016

\section{Keywords:}

Tungro viruses

Recombinant fusion protein

Antibody

Serological assays

\begin{abstract}
A B S T R A C T
Rice tungro disease (RTD) is a recurring disease affecting rice farming especially in the South and Southeast Asia. The disease is commonly diagnosed by visual observation of the symptoms on diseased plants in paddy fields and by polymerase chain reaction (PCR). However, visual observation is unreliable and PCR can be costly. High-throughput as well as relatively cheap detection methods are important for RTD management for screening large number of samples. Due to this, detection by serological assays such as immunoblotting assays and enzyme-linked immunosorbent assay are preferred. However, these serological assays are limited by lack of continuous supply of antibodies as reagents due to the difficulty in preparing sufficient purified virions as antigens. This study aimed to generate and evaluate the reactivity of the recombinant coat proteins of Rice tungro bacilliform virus (RTBV) and Rice tungro spherical virus (RTSV) as alternative antigens to generate antibodies. The genes encoding the coat proteins of both viruses, RTBV (CP), and RTSV (CP1, CP2 and CP3) were cloned and expressed as recombinant fusion proteins in Escherichia coli. All of the recombinant fusion proteins, with the exception of the recombinant fusion protein of the CP2 of RTSV, were reactive against our in-house anti-tungro rabbit serum. In conclusion, our study showed the potential use of the recombinant fusion coat proteins of the tungro viruses as alternative antigens for production of antibodies for diagnostic purposes.
\end{abstract}

(c) 2016 Elsevier B.V. All rights reserved.
Rice tungro disease (RTD) is a composite disease caused by Rice tungro bacilliform virus (RTBV) and Rice tungro spherical virus (RTSV) (Hibino et al., 1978; Cabautan and Hibino, 1988; Jones et al., 1991). RTSV, which assists in the transmission of RTD, is a single-stranded ribonucleic acid (RNA) picorna-like virus belonging to the family Sequiviridae (Zhang et al., 1993; Sanfacon et al., 2009). Meanwhile, RTBV, the real causative agent of the disease, has a double-stranded circular deoxyribonucleic acid (DNA) and is a pararetrovirus in the family Caulimoviridae (Bousalem et al., 2008; Geering et al., 2010). A rice plant infected by both of the viruses will show severe symptoms of yellow-orange leaf discoloration, stunted growth and reduced yield. An infection by RTBV alone will cause milder symptoms (Hibino et al., 1990). RTBV and RTSV are semi-persistently transmitted by the green leafhopper, especially the Nephotettix virescens species (Hibino, 1983a,b). Managing RTD is a challenge in sustaining food security in South and Southeast Asia where rice

\footnotetext{
* Corresponding author.

E-mail addresses: shsmag@ihcm.unimas.my, magdline.sum@gmail.com (M.S.H. Sum).
}

is the main food staple for the populations. For many small-scale farmers, planting rice is their main source of livelihood (Azzam and Chancellor, 2002; Norsida and Sami, 2009). Hence, monitoring of the disease is important to prevent enormous losses. Currently polymerase chain reaction (PCR) methods, detecting viral nucleic acids are used for laboratory confirmation of the disease to compliment visual observation. However this method may not be suitable especially for rural areas where the facilities are not adequately equipped, furthermore it can be costly for detection of large number of samples. The ideal detection method for monitoring RTD needs to be reliable, simple, fast, relatively inexpensive and can perform high-throughput detection of samples.

Immunoblot assays such as dot blot and tissue blot assays have the mentioned capacities (Hu et al., 1995; Fitch et al., 2001; Whitfield et al., 2003; Meng et al., 2003; Abou-Jawdah et al., 2004; Lin et al., 2006; Wu et al., 2013). However, a long term application of serological assays in diagnosing RTD is only practicable with constant source of antibodies. Maintaining sufficient supply of purified tungro virions as the antigen source, can be an issue due to the difficulty in obtaining high yield of purified virions. To overcome this problem, one approach is to substitute the use of purified virions 